\title{
Integrated Risk Assessment of Multiple Air Pollutants and Influence Factors in an Urban Agglomeration of China
}

\author{
Wenli Feng ${ }^{1,2 *}$, Yongfang Zhang ${ }^{1 * *}$, Shuge Wang ${ }^{1}$, Mengyao Xu' ${ }^{1}$, Yunlin Li ${ }^{1,2}$, Ping \\ Wang $^{1,2}$, Chaosheng Zhu ${ }^{1,2}$, Songfang Han ${ }^{1,2}$, Lei Shi ${ }^{3}$, Yifei Guo ${ }^{4}$ \\ ${ }^{1}$ School of Chemistry and Chemical Engineering, Zhoukou Normal University, Zhoukou, 466001, China \\ ${ }^{2}$ Zhoukou Key Laboratory of Environmental Pollution Control and Remediation, Zhoukou Normal University, \\ Zhoukou, 466001, China \\ ${ }^{3}$ School of Environmental and Biological Engineering, Henan University of Engineering, Zhengzhou, 451191, China \\ ${ }^{4}$ Henan Key Laboratory of Water Pollution Control and Rehabilitation Technology, Henan University of Urban \\ Construction, Pingdingshan, 467036, China
}

Received: 25 October 2020

Accepted: 26 February 2021

\begin{abstract}
There has been an increasing interest in evaluating health effects associated with multiple air pollutants. Identifying the critical factors driving the variation of multiple air pollutants and pollution caused the human health risk are still limited. We selected four typical cities as the study object in the Central Plains Urban Agglomeration (CPUA), China and collected the data of air pollutants, meteorological factors and social development factors over the two years. Our results showed that the air pollutants presented remarkable seasonal variations, according to the principal coordinate analysis (PCoA), the air pollution event often occurred in winter in the CPUA, and the air quality health index (AQHI) values were moderate risk for population health particularly in Zhengzhou and Anyang. The results of the correlation analysis and redundancy analysis (RDA) showed that air pollution and associated health risk was driven by human activities, and was influenced by dominant meteorological factors, such as, rainfall, vapor pressure, relative humidity. These indicated that the air pollution in the CPUA should make the pollutant emission plan according to the region and season to improve the air quality and protect the public health.
\end{abstract}

Keywords: air pollution, health risk, Air Quality Health Index, urban agglomeration

\footnotetext{
*e-mail: wlfeng@zknu.edu.cn
}

**e-mail: yfzhang1988@126.com 


\section{Introduction}

The effects of rapid urbanization and developing urban agglomerations on environmental pollution had been verified by many studies [1-3]. The influences of air pollution on human health and ecosystem are widely concerned on the field of environmental protection. As officially reported, China's urbanization rate increased from $10.64 \%$ in 1949 to $59.58 \%$ in 2018, which was driven by large-scale demographic migration and social and economic development. Urbanization not only drives social development, human civilization and technological invention, but also accelerate the population density and the energy and resource consumption, and causes the environment problem [4-6]. For example, current study found that a $0.167 \%$ increase in $\mathrm{PM}_{2.5}$ concentrations, for every $1 \%$ increase in population density in the Yangtze river delta (YRD) region [7]. On a worldwide basis, $91 \%$ populations are exposed to undesirable air quality, which were closely related to both chronic and acute cardiovascular and respiratory diseases, even death [8].

Atmospheric pollutants, such as particulate matter $\left(\mathrm{PM}_{2.5}\right.$ and $\left.\mathrm{PM}_{10}\right)$, [9], nitrogen dioxide $\left(\mathrm{NO}_{2}\right)$ [10], ozone $\left(\mathrm{O}_{3}\right)$ [11], carbon monoxide $(\mathrm{CO})$ and sulfur dioxide $\left(\mathrm{SO}_{2}\right)[12,11]$, have drawn great public attention, due to be associated with a wide range of effects on human health [13]. Epidemiological studies have shown that $\mathrm{PM}_{2.5}$ can attach the pollutants and enter human respiratory system, even penetrate through lung cells into the blood circulation [14], it brings harms to human health. Similarly, gaseous pollutants in the air can also affect the physical activity and pathological state of the body [13]. In most cases, people are exposed to multiple pollutants in daily life. Meanwhile, the atmosphere is a complex dynamic system with multiple pollutants interactions. It is difficult to explain the influence mechanism of cooperation of multiple pollutants on human health [15]. Therefore, many studies recommended aggregate risk index instead of single pollutant risk [16, 17]. The Air Quality Index (AQI) and Air Pollution Index (API) has been widely used to assess the quality of ambient air [18, 19], which used to aim to meet the management rather than reflect the direct relations between pollutants and health risk [20, 21]. A new multipollutant air quality health index (AQHI) was proposed in Canada, which was based on the total of excess mortality risk associated with individual pollutants from a time-series analysis. [21] At present, the evaluation system of AQHI has been established in some cities in China, such as, Lanzhou [22], Shanghai [20], Guangzhou [23], and Hong Kong [24]. These results show that the AQHI can help understand the sum of short term health risk of air pollution mixture. Thereafter, it is necessary to establish the nationwide evaluation system based on the AQHI, of course, more research is needed to improve this system.

The variations of air pollutants are often influenced by various environmental and anthropogenic factors [25]. Therefore, the human health risks initiated by pollutants are also affected by these factors, such as hydrometeorological factors, topographical factor and economic and social indicators. The current study from western China reported that spatiotemporal changes of pollutants were correlated with the residential emissions, indicating that the reduction of anthropogenic emissions was needed to improve the local air quality [26]. However, the results showed that the influence of factors on air pollutants emissions vary by region [27]. Air pollutants as risk factors for respiratory diseases of children and adults were verified by numerous work [8]. In addition, the health effects estimates might be different from age, seasonal changes and regional development [7]. The variations of different air pollutant vary in stages and regional scale, such as, the fluctuation of $\mathrm{O}_{3}$ variation curve is very different from other air pollutants. Thus, the interaction among air pollutants, influence factors and health risk can also be seen as a complex dynamic process. Previous studies paid much attention to the effect of environmental factors on a single pollutant, which could not accurately reflect actual circumstances [28, 29]. In addition, many studies did not take into account the effect of anthropogenic source, namely, emission source [30], which have adverse effects on making the strategies of air pollution control.

The Central Plains Urban Agglomeration (CPUA) has the highest rate of urbanization and highest population density in China, and the development planning of the region has been upgraded to a national strategy. In this paper, four typical cities in the CPUA were selected to investigate the influence of environmental and anthropogenic factors on the dynamic change of multiple air pollutants and associated health risk. Specifically, the main objectives of this study are to: (1) describe the spatiotemporal characteristics of six pollutants in the ambient air of CPUA; (2) investigate the dominant factors influencing the 
pollutants and health risk; (3) illustrate the variation mechanisms of pollutants and the health risk at a regional scale. Also note that the multivariate statistical analysis was employed to achieve the goal mentioned above. The results can enhance the understanding of the critical factors driving the occurrence of air pollution events and the risk of adverse health conditions, which also assist policymakers set priorities and make the control strategy for the regional air quality management.

\section{Methods and Materials}

\section{Study Area}

As shown in Fig. 1, the CPUA region is located in central and eastern part of China, including 30 cities in five provinces, which covers roughly $287,000 \mathrm{~km}^{2}$ with the population of 163.53 million, and of these, 14 cities are located in the core area of the CPUA. The region is becoming China's important economic growth pole, due to the convenient multimodal transportation, improved logistics network and developed manufacturing industry. According to the previous work, the typical cities in the CPUA region, such as Zhengzhou, Xinxiang and Anyang in Henan province, had suffered serious air pollution due to the complex interaction between intensive pollutants emissions and unfavorable meteorological conditions $[31,32]$. The region is subject to a temperate continental monsoon. The annual average temperature is $12.7^{\circ} \mathrm{C}-16.2^{\circ} \mathrm{C}$, with an annual average humidity of $60 \%-80 \%$, and the sunshine duration is $1468-2247 \mathrm{~h}$, the average frost-free period 208$272 \mathrm{~d}$. The average annual precipitation ranges from 477.8 to $1167.3 \mathrm{~mm}, 50 \%$ of the annual precipitation concentrated mostly in Summer (June to August).

\section{Data Sources}

The monthly data of $\mathrm{AQI}$ and air pollutants including $\mathrm{PM}_{2.5}, \mathrm{PM}_{10}, \mathrm{SO}_{2}, \mathrm{CO}, \mathrm{NO}_{2}$ and $\mathrm{O}_{3}$ were collected in the China National Environmental Monitoring Center, from September 2017 to August 2019. In this study, the influence factors including the meteorological factors and social economic indicators, which represent the environmental and anthropogenic factors, respectively. The meteorological data at the monitoring sites, including rainfall amount, precipitation days $(>0.1 \mathrm{~mm})$, air temperature, atmosphere and vapor pressure, relative humidity, wind speed, and sunshine duration were provided by the China Data Centre for Meteorology. The industrial electricity and total social electricity consumption data were obtained from the monthly economic report of the local the official website of government. The data sources statistic results of these data are introduced in detail in the supporting information.

\section{Assessment Method}

The AQI has replaced the API to assess the air quality in 2012 in China. The AQI measures the overall quality of the air, which can meet

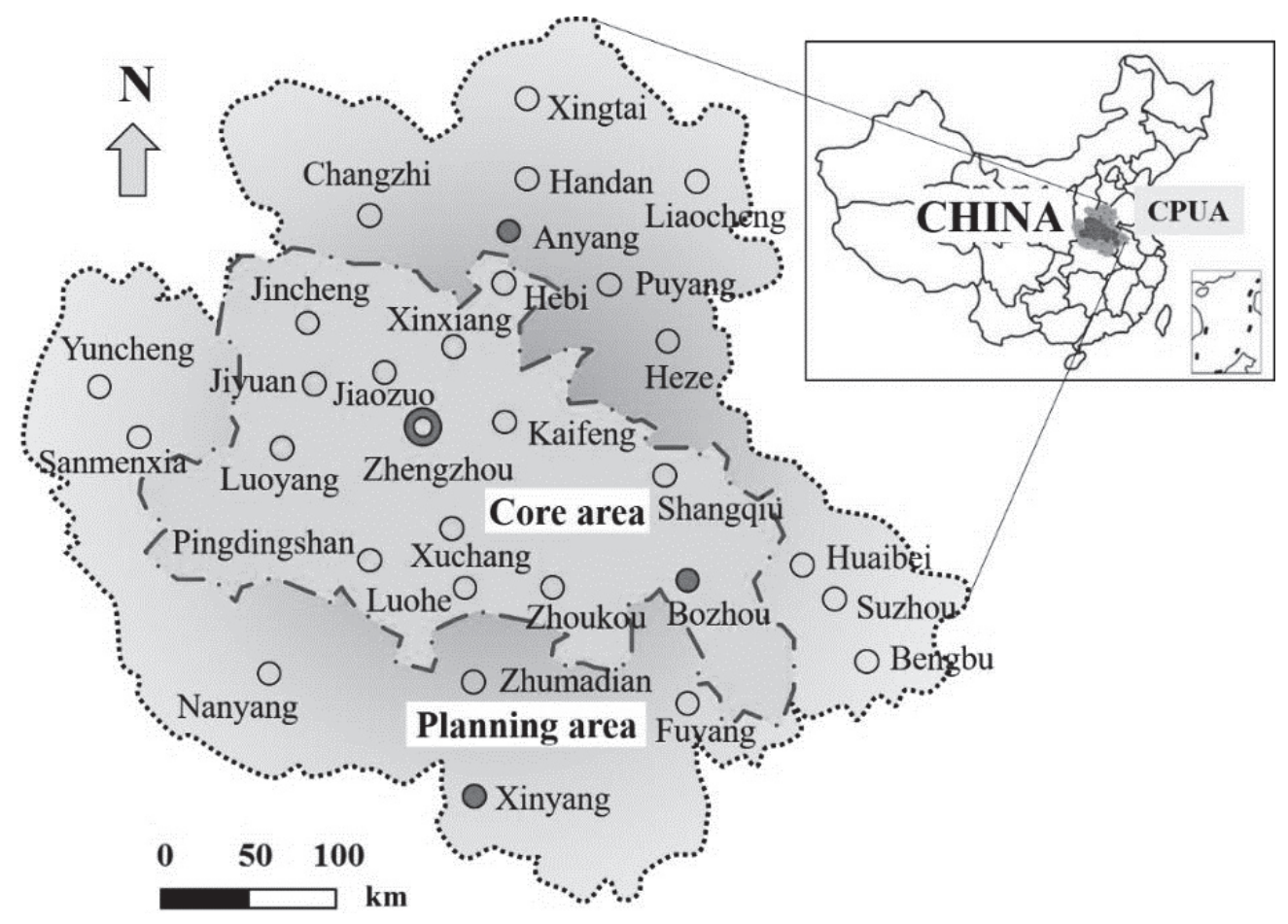

Fig. 1. Location of the Central Plain Urban Agglomeration (CPUA) region of China. 
the air quality management goal. Although the AQI have been used successfully in various country, it could neither present the effect of multiple air pollutants on the health risk nor reflect the relationships between the two (Stieb, et al., 2008; Chen, et al., 2013). In order to fill the gap of the AQI, the AQHI methods had been developed based on the relation between mortality and associated health risk [21]. Generally, the AQHI can reflect the health effects of air pollution from the perspective of the epidemiology in the general population and directly provide the information about the health risks for the public [13]. The calculation of $\mathrm{AQHI}$ is shown in Eq. (1):

$$
\mathrm{AQHI}=(10 / c) \sum_{i=1 \cdots n} 100\left[\exp \left(\beta_{i} x_{i}\right)-1\right]
$$

...where $\beta i$ is the coefficient of Poisson regression model, $x_{i}$ is the concentration of the pollutant $i$. The $c$ is the scaling factor, and the value is $16.4 \%$ [20]. Due to the AQHI is an unbounded index, on a $0-10+$ scale, which has four bands, including "Low (0-3 ), Moderate (4-6), High (6-9) and Very High $(>10)$ risk" of increase [17, 21]. In this study, the AQHI was determined using the derived model based on the data of "The China Air Pollution and Health Effects Study" [13, 20]:

$$
\begin{aligned}
\mathrm{AQHI}= & (10 / 16.4) \times 100 \times\left[\exp \left(0.00019 \times \mathrm{PM}_{10}\right)\right. \\
& \left.-1+\exp \left(0.00061 \times \mathrm{NO}_{2}\right)-1\right]
\end{aligned}
$$

\section{Statistical Analysis}

The normality test of data was determined by the non-parametric Kolmogorov-Smirnov $(K-S)$ test, and non-normal data were processed using $\log 10$ transformation [5, 33]. One-way ANOVA was used to identify differences among groups of variables using a Tukey's post hoc with a significance $<0.05$ [5]. The principal coordinate analysis (PCoA) by the Bray-curtis distance metric was adopted to identify association among air pollutants [34]. In order to investigate the relationship among air pollutants, risk index and influence factors, a redundancy analysis (RDA), which is a direct gradient analysis technique and has been widely used in environmental and ecological studies $[5,35]$. The $K-S$ test and Oneway ANOVA were performed by the software SPSS statistic 19.0, and RDA and PCoA were done by software Canoco 5.0.

\section{Results and Discussion}

\section{General Characteristics of Air Pollutants}

The mass concentrations of the air pollutants at four sites are shown in Fig. 2a). During the study period, the monthly concentrations of the $\mathrm{PM}_{2.5}$ varied from $20-156 \mu \mathrm{g} / \mathrm{m}^{3}$ with the average of $57 \mu \mathrm{g} / \mathrm{m}^{3}$. For the $\mathrm{PM}_{10}$, the values varied from $36-195 \mu \mathrm{g} / \mathrm{m}^{3}$ with the mean of $95 \mu \mathrm{g} / \mathrm{m}^{3}$. The $\mathrm{SO}_{2}$ concentrations varied from $4-35 \mu \mathrm{g} / \mathrm{m}^{3}$ with an average of $13 \mu \mathrm{g} / \mathrm{m}^{3}$, and $\mathrm{CO}$ concentrations ranged from $0.355-2.303 \mathrm{mg} / \mathrm{m}^{3}, 0.989 \mathrm{mg} / \mathrm{m}^{-3}$. For the $\mathrm{NO}_{2}$ and $\mathrm{O}_{3}$, the values ranged from $11-68 \mu \mathrm{g} / \mathrm{m}^{3}$ (mean of $35 \mu \mathrm{g} / \mathrm{m}^{3}$ ) and $33-205 \mu \mathrm{g} / \mathrm{m}^{3}$ (mean of $106 \mu \mathrm{g} / \mathrm{m}^{3}$ ). Through the $K-S$ test, the distributions of $\mathrm{PM}_{2.5}$ and $\mathrm{SO}_{2}$ values are disobedient normally distribution $(P<0.05)$, and may be the skewed distribution. From current study, the total pollution levels in the CPUA may have dropped compared with passed years since the policy of control emission was implemented in current years [31]. For example, the daily average concentration
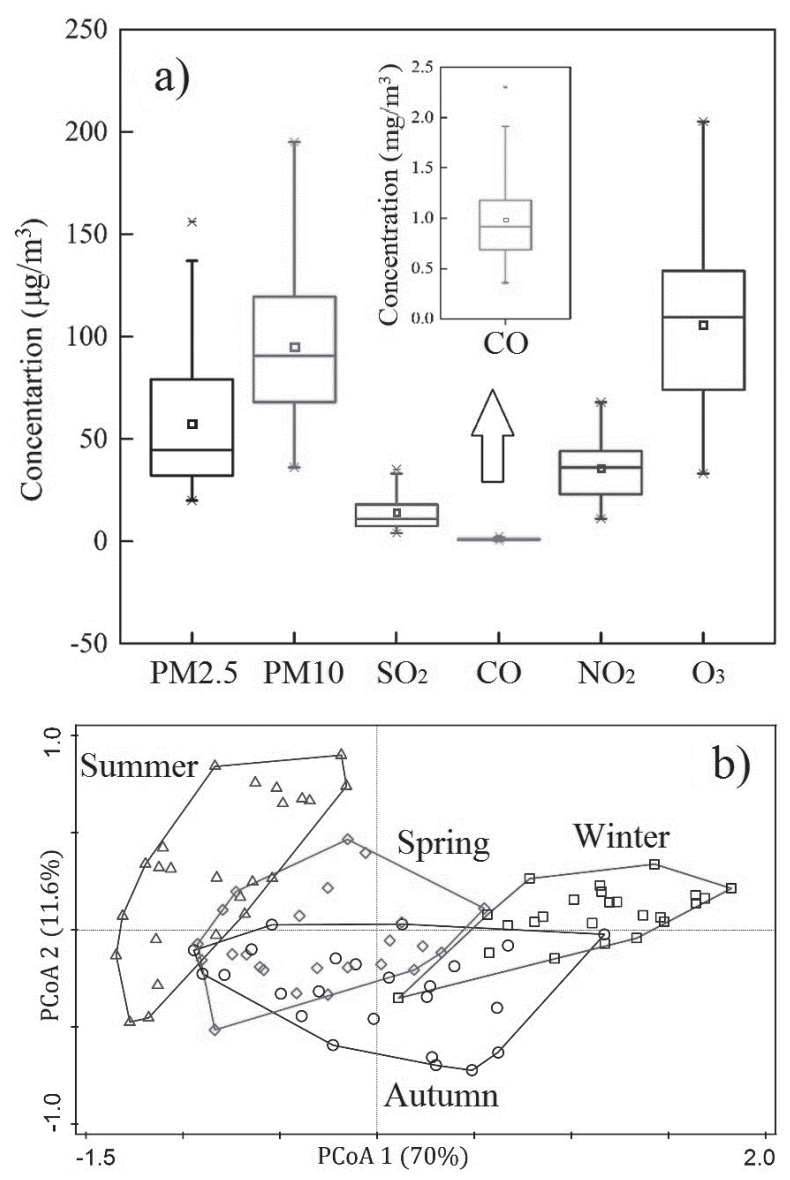

Fig. 2. The concentrations of air pollutant in the CPUA. a) In this box-whisker plots, the whiskers and boxes indicated the $95^{\text {th }}, 75^{\text {th }}, 50^{\text {th }}$ (median), $25^{\text {th }}$ and $5^{\text {th }}$ percentiles, respectively. b) Principal coordinate analysis ( $\mathrm{PCoA})$ using the Bray Curtis matrix distance based on air pollutants data classified by season in the CPUA. 
of $\mathrm{PM}_{2.5}$ observed in 2017 and the pollution days much less than those in 2014 to 2015 in Zhengzhou [36, 31].

As shown in Fig. 3, the monthly variations of most air pollutants over the two years were similar in the CPUA, the higher values were observed from November to next February, which also indicated that the air pollution event was related to these pollutants usually occurred in winter. In contrast, the lower values of $\mathrm{O}_{3}$ were observed in the same period. The results of PCoA based on the air pollutants data also shown that the air pollution in winter was significant heavier than other seasons $(P<0.05)$, and the air pollution in summer was also significant lower than other seasons in the CPUA (Fig. 2b). These results are consistent with the previous studies in the CPUA [37]. It can be concluded that the fluctuating air pollutants may be the results from the influence of the driving factors changes in different season.
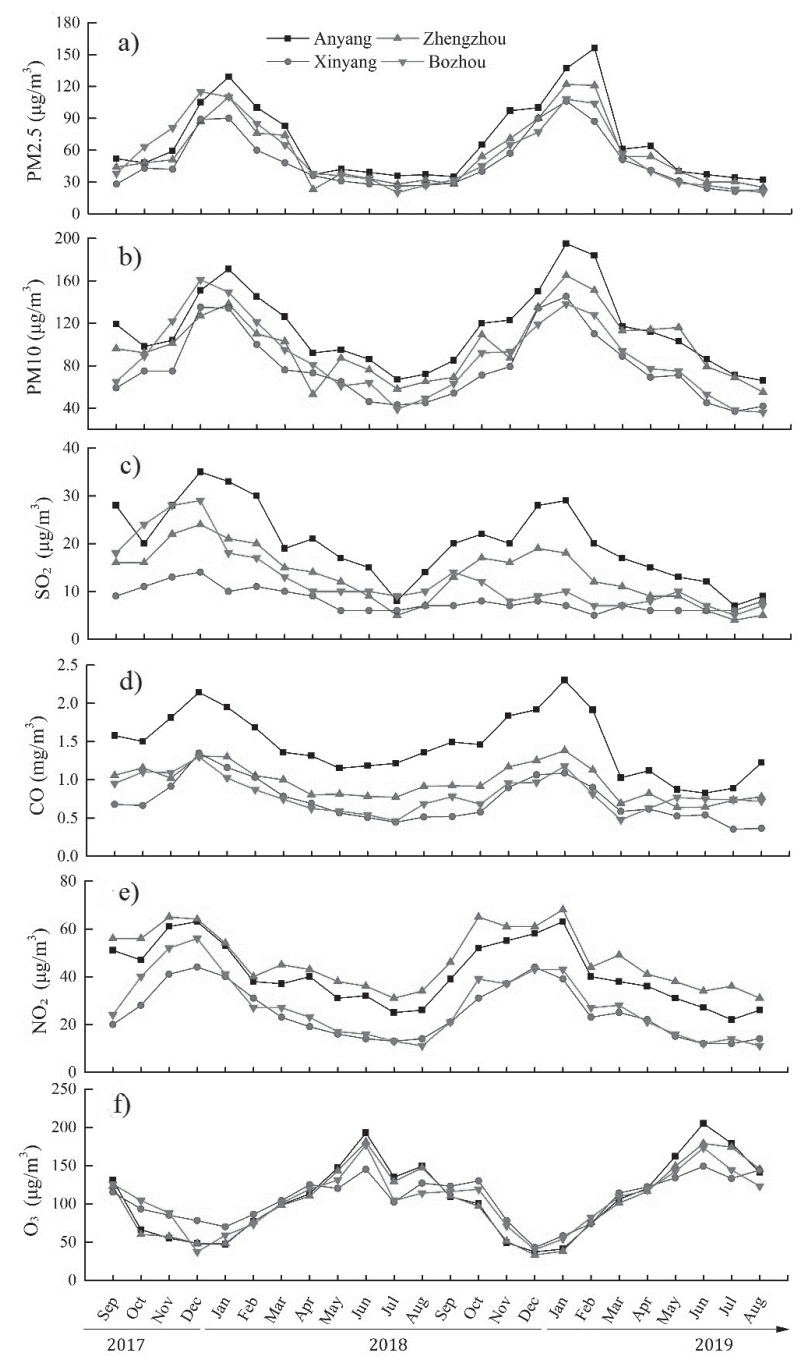

Fig. 3. Temporal variations in concentrations of air pollutants in the CPUA from September 2017 to August 2019.

\section{$\mathrm{AQI}$ and $\mathrm{AQHI}$}

The AQHI was calculated according to the concentrations of multiple pollutants, and the results are shown in Fig. 4. The results shown that the tendency of AQHI varied with the month was similar with AQI in four cities of the CPUA. Obviously, the values were higher in winter than those in spring and summer. The AQHI presented stepped distribution, due to the AQHI was used as integers. According to the AQHI risk classification, the values were within the low and moderate risk in winter, such as the AQHI values in winter in Anyang and Zhengzhou were the moderate risk. These results indicated that the fluctuant AQHI varied with the pollutant concentration, and also influenced by other environmental factors. The reasons might be the pollutants variation were depended on environmental and emission factors. Nationally, a rise of one unit in AQHI, the mortality increase by $0.97 \%$, which also vary by the age, gender and other factors [20]. Thus, the critical factors influencing AQHI, AQI and air pollutants should be ascertained.

\section{Influencing Factors}

The statistical results of environmental factors meteorological factors, such as rainfall amount,
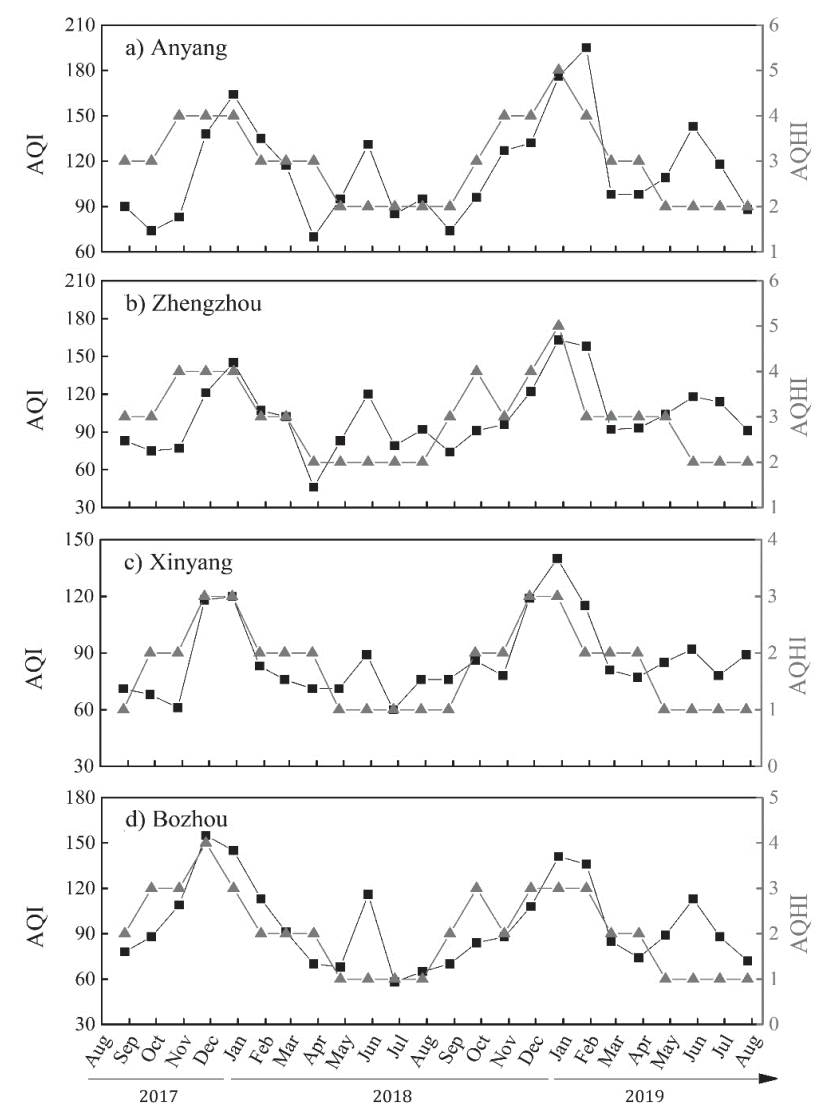

Fig. 4. Air Quality Index (AQI) and Air Quality Health Index (AQHI) in four cities of the CPUA. For the AQHI, low risk: 0-3, Moderate risk: 4-6, High risk: 6-9 and very high risk: $>10$. 
atmosphere pressure, wind speed, air temperature, vapor pressure, relative humidity, precipitation days $(>0.1 \mathrm{~mm} / \mathrm{d})$, sunshine duration, and social development indicators, such as industrial electricity consumption and total electricity consumption. The average monthly rainfall was $59.5 \mathrm{~mm}$ with a range from 0 to $254.4 \mathrm{~mm}$ during the study period in the CPUA. The rainfall concentrated mostly in Spring and Summer when the southeast monsoon carries rainwater into the plain area. Therefore, the number of precipitation days was often more in this periods than that in other seasons. Moreover, some meteorological factors varied with the season changes. Such as, atmosphere pressure, wind speed, air temperature, vapor pressure, air temperature and sunshine duration presented a regularly change pattern. These findings indicated that the interaction among these factors might play an important role in influencing materials transport and diffusion and these factors had different effects on the air pollution process.

The low electricity consumptions were observed in November and December, and the high electricity consumptions were recorded in July and August in the CPUA, the electricity consumption may increase with the increase of city size and population. Note that the total and industrial electricity consumption in four cities present similar annual tendency of variation, which suggesting some connections between the total and industrial electricity consumption.

\section{Relationships Among Air Pollutants, Indices and Factors}

Fig. 5 showed that the relations among air pollutants, AQI, AQHI and environmental factors in the CPUA. As shown in Fig. 5, the Eigenvalues of the axis 1 and axis 2 were 0.68 and 0.06 , the correlation coefficients between species and factors were 0.95 and 0.83 respectively. Two axes of RDA together explained $74.0 \%$ of the total variance, the axis 1 and axis 2 explained $67.6 \%$ and $6.4 \%$ of those, respectively. The correlation analysis shown that these factors, such as vapor pressure, air temperature, rainfall amount and precipitation days were significantly and positively correlated with axis 1 , and negatively correlated with most air pollutants such as $\mathrm{PMs}, \mathrm{CO}, \mathrm{SO}_{2}$ and $\mathrm{NO}_{2}$, and AQHI and AQI $(P<0.01)$, which indicated that increasing values of these factors could decrease the concentrations of most air pollutants and improve the air quality and population health. Conversely, these could increase the concentrations of $\mathrm{O}_{3}$ in atmosphere. These results further suggesting that the RDA ordination axes can reflect well on the environment gradients.

Fig. 5b) showed the effects of environmental factors on the air pollution and air quality during winter in the CPUA. According to the former analysis, the air pollution event occurs most often during winter, especially for northeastern cities of Anyang and Zhengzhou. The Eigenvalues of the axis 1 and axis 2 are 0.59 and 0.12 , correlation coefficients between species and factors are 0.94 and 0.86 , respectively. The first 2 axes of RDA explained $70.9 \%$ of the total variance, the axis 1 and axis 2 explained $59.0 \%$ and $12.0 \%$, respectively. Axis 1 was significantly correlated with vapor pressure, precipitation days, relative humidity, rainfall amount, industrial and total electricity consumption $(P<0.05)$. The AQI, AQHI and most air pollutants were positively and significantly correlated with the industrial and total electricity consumption,
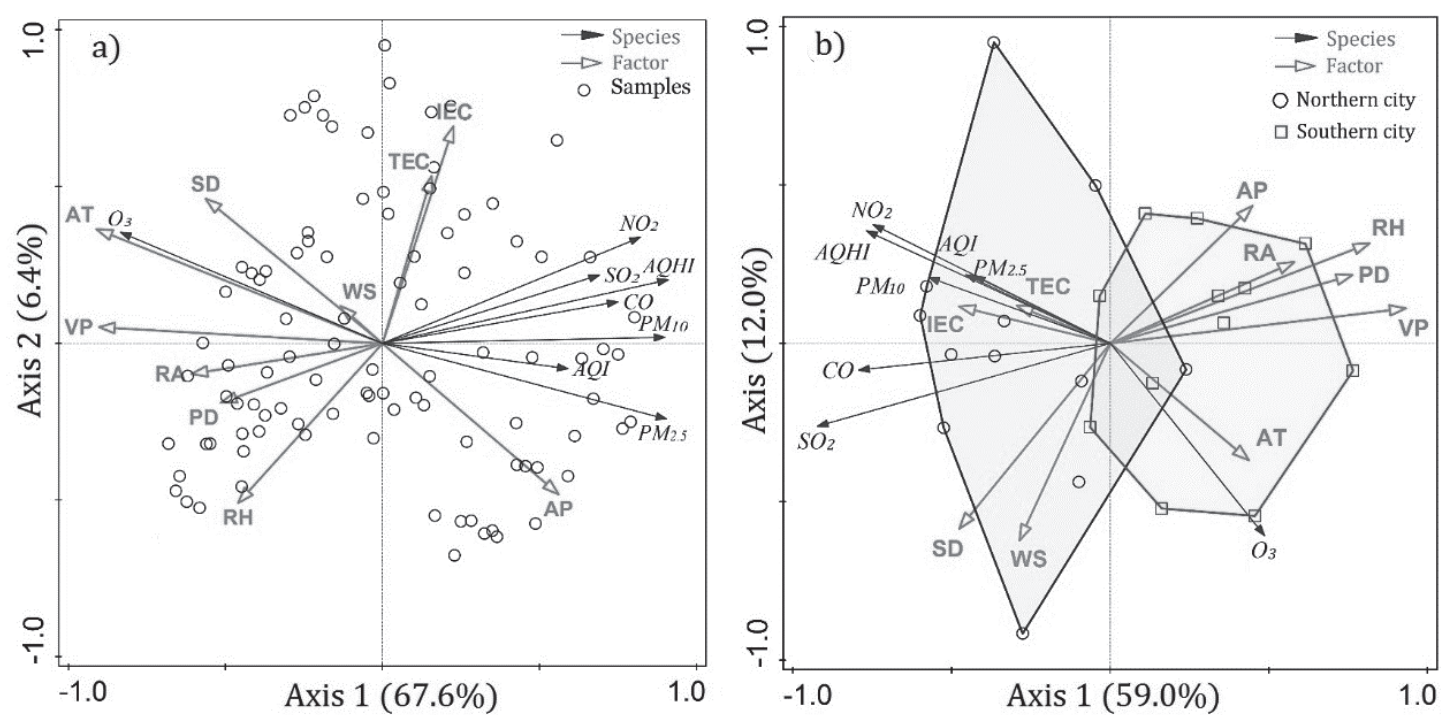

Fig. 5. Bioplot of RDA showing the relationships between air pollutant, indices and environmental factors over two years a) and Winter b) in the CPUA. The red arrows represent environmental factors, and the blue ones represent the air pollutants and indices. RA: Rainfall amount, mm; AP: Atmosphere pressure, hPa; WS: Wind speed, m/s; AT: Air temperature, ${ }^{\circ} \mathrm{C}$; VP: Vapour pressure, hPa; RH: Relative humidity, \%; PD: Precipitation days $>0.1 \mathrm{~mm}, \mathrm{~d}$; SD: Sunshine duration, h; IEC: Industrial electricity consumption, billion kW h; TEC: Total electricity consumption, billion $\mathrm{kW} \mathrm{h}$. The length of arrows denotes the influencing degree of these selected factors on air pollutants and indices. 
and negatively correlated with vapor pressure, precipitation days, relative humidity, rainfall amount. The Monte Carlo test showed that rainfall, vapor pressure and relative humidity were critical factors that influenced air pollution in winter. In addition, the results revealed the relationships between air pollution and environmental factors in northern and southern cities of the CPUA. The data were collected in the urban of four cities during winter and clearly clustered into two groups, namely, southern area and northern area. For example, in the northern area, the data of pollutant and air quality were closely linked to electricity consumption, and those were rainfall, vapor pressure and relative humidity for southern areas. Through the above analysis, the results indicated that rainfall, vapor pressure, relative humidity and electricity consumption were critical factors that affect the air quality and population health risk. Therefore, the air pollution and associated health risk in the CPUA were driven by various human activities, and also influenced by dominant meteorological factors.

The critical factors play an important role in driving the changes of air pollutants, the air quality and population health. In this study, most air pollutants present the significant and positive relations, except for the $\mathrm{O}_{3}$ (Fig. 5), which were similar with previous studies. These may be due to the difference in environmental behavior among pollutants. As the result of previous studies, $\mathrm{O}_{3}$ formation should be concerned when controlling $\mathrm{PM}_{2.5}$, because of the $\mathrm{O}_{3}$ is a secondary pollutant generated from photochemical reactions of some gaseous pollutants, such as, the oxy-nitride (NOx) and volatile organic compounds (VOCs) [6, 38]. Additionally, the concentrations of pollutants can also influence the $\mathrm{O}_{3}$ concentration, for example, due to the controlling of particular matters reduced the scattering and absorption of sunlight, increased UV radiation, and led to higher $\mathrm{O}_{3}$ [6]. Furthermore, some factors are closely related to the $\mathrm{O}_{3}$ concentration, for example, lower temperature can slow the photochemical reaction, and further decrease the $\mathrm{O}_{3}$ concentration in the air. Many factors have higher relevance and particularity in temporal distribution, such as the rainfall activity (RA and PD) is likely to increase humanity (RH), and vapor pressure (VP), this can decrease the concentrations of most pollutants and further improve the air quality. In the CPUA, heavily influenced by monsoon climate, the volume of rainfall is quite unevenly distributed, causing rainstorm often to happen in summer, and the air temperature in the season is also higher. Therefore, the air pollution events tend to occur in winter, with the lower temperature, lower pressure, and less rainfall, which lead to form the steady atmospheric stratification and hinder the diffusion of pollutants and degradation [28]. In the study area, it has become an urgent problem how to control the air pollution in winter, improve the air quality and decrease the risk of population health.
In this study, we used the electricity consumption to represent the influences of human activities. The results showed that the air pollution or air quality was closely to the electricity consumption (Fig. 4.), suggesting that the impacts of human activities on air pollution can be well-represented by electricity consumption. The contribution of air pollutant from anthropogenic emissions to affect air quality and population health should not be neglected $[39,26]$. The current study in the CUPA showed that the emissions of $\mathrm{SO}_{2}, \mathrm{PM}_{10}, \mathrm{PM}_{2.5}, \mathrm{NO}_{\mathrm{X}}$ and $\mathrm{CO}$ are about 1.24, 1.29, $0.70,1.93,7.92$ million tons, respectively, which come from the local region, particularly Zhengzhou and Pingdingshan [40]. In addition, the AQHI was used to represent the air quality, which can identify and develop new indicator to monitor air pollution-related health outcomes within surveillance systems. However, in some epidemiological cases, even the low concentration of some air pollutants is also harmful to population health $[41,13,2]$. Therefore, it is essential to establish the improved aggregate index including multiple air pollutants, such as $\mathrm{O}_{3}, \mathrm{NOx}$ and VOCs, etc. Although a simple method was recommended to calculate the AQHI for assessing the air quality from the population health standpoint, which can also to fill gaps in the study of CPUA, which was believed can help understand the overall health impacts of multiple air pollutants.

\section{Conclusions}

In this study, current two-years data including multiple air pollutants, environmental factors were conducted at the four typical cities in the CPUA to determine the relationships among air pollutants, air quality, health risk and factors. The results showed that, the air pollutants presented the remarkable seasonal variations, according to the analysis of PCoA, the air pollution event often occurred in winter in the CPUA, and the AQHI were moderate risk for population health particularly in Zhengzhou and Anyang. The results of RDA showed that the air pollution and associated health risk in the CPUA was driven by human activities, and was influenced by dominant meteorological factors, such as, rainfall, vapor pressure, relative humidity. Our study provided a method to analysis the variations of multiple air pollutants and to explore the driving factors of pollution. The results provided meaningful understanding to formation mechanism of combined air pollution and possible emission control strategies in the CPUA, China.

\section{Acknowledgments}

This work was supported by Key $R \quad \& \quad D$ and Promotion Projects of Henan Province (No. 
202102310268, 212102310531 and 212102310067), Natural Science Foundation of Henan Province (No. 202300410521), College Students' Science and Technology Innovation Project (No. ZKNUD2021060, ZKNUD2021061) and Scientific Research Foundation for High-level Professionals of Zhoukou Normal University (No. ZKUNC2019002).

\section{Conflict of Interest}

The authors declare that they have no competing interests.

\section{References}

1. PENG C., OUYANG Z., WANG M., CHEN W., LI X., CRITTENDEN J.C. Assessing the combined risks of PAHs and metals in urban soils by urbanization indicators. Environmental Pollution, 178, 426, 2013.

2. CHENG Z., LI L., LIU J. Identifying the spatial effects and driving factors of urban $\mathrm{PM}_{2.5}$ pollution in China. Ecological Indicators, 82, 61, 2017.

3. LIANG L., WANG Z., LI J. The effect of urbanization on environmental pollution in rapidly developing urban agglomerations. Journal of Cleaner Production, 237, 117649, 2019.

4. FENG W., GUO Z., PENG C., XIAO X., SHI L., HAN X., RAN H. Modelling mass balance of cadmium in paddy soils under long term control scenarios. Environmental Science: Processes and Impacts, 20 (8), 1158, 2018.

5. FENG W., GUO Z., PENG C., XIAO X., SHI L., ZENG P., RAN H., XUE Q. Atmospheric bulk deposition of heavy metal(loid)s in central south China: Fluxes, influencing factors and implication for paddy soils. Journal of Hazardous Materials, 371, 634, 2019.

6. WANG K.L., MIAO Z., ZHAO M.S., MIAO C.L., WANG Q.W. China's provincial total-factor air pollution emission efficiency evaluation, dynamic evolution and influencing factors. Ecological Indicators, 107, 105578, 2019.

7. LOU C.R., LIU H.Y., LI Y.F., LI Y.L. Socioeconomic Drivers of $\mathrm{PM}_{25}$ in the Accumulation Phase of Air Pollution Episodes in the Yangtze River Delta of China. International Journal of Environmental Research and Public Health, 13(10), 928, 2016.

8. HACHEM M., SALEH N., PAUNESCU A., MOMAS I., BENSEFA-COLAS L. Exposure to traffic air pollutants in taxicabs and acute adverse respiratory effects: A systematic review. Science of the Total Environment, 693, 133439, 2019.

9. SULAYMON I.D., MEI X., YANG S., CHEN S., ZHANG Y. $\mathrm{PM}_{25}$ in Abuja, Nigeria: Chemical characterization, source apportionment, temporal variations, transport pathways and the health risks assessment. Atmospheric Research, 237, 104833, 2019.

10. ROJAS A.L.P., VENEGAS L.E. Upgrade of the DAUMOD atmospheric dispersion model to estimate urban background $\mathrm{NO}_{2}$ concentrations. Atmospheric Research, 120, 147, 2013.

11. GAUR A., TRIPATHI S.N., KANAWADE V.P., TARE V., SHUKLA S.P. Four-year measurements of trace gases $\left(\mathrm{SO}_{2}, \mathrm{NOx}, \mathrm{CO}\right.$, and $\left.\mathrm{O}_{3}\right)$ at an urban location, Kanpur, in
Northern India. Journal of Atmospheric Chemistry, 71 (4), 283, 2014.

12. LI K., CHEN L., WHITE S.J., HAN K., LV B., BAO K., WU X., GAO X., AZZI M., CEN K. Effect of nitrogen oxides $\left(\mathrm{NO}\right.$ and $\mathrm{NO}_{2}$ ) and toluene on $\mathrm{SO}_{2}$ photooxidation, nucleation and growth: A smog chamber study. Atmospheric Research, 192, 38, 2017.

13. CHEN R., KAN H., CHEN B., HUANG W., BAI Z., SONG G., PAN G. Association of Particulate Air Pollution With Daily Mortality: The China Air Pollution and Health Effects Study. American Journal of Epidemiology, 175 (11), 1173, 2012.

14. MANIGRASSO M., VITALI M., PROTANO C., AVINO P. Ultrafine particles in domestic environments: Regional doses deposited in the human respiratory system. Environment International, 118, 134, 2018.

15. OAKES M., BAXTER L., LONG T.C. Evaluating the application of multipollutant exposure metrics in air pollution health studies. Environment International, 69, 90, 2014.

16. MASON T.G., SCHOOLING C.M., CHAN K.P., TIAN L. An evaluation of the air quality health index program on respiratory diseases in Hong Kong: An interrupted time series analysis. Atmospheric Environment, 211, 151, 2019.

17. SICARD P., TALBOT C., LESNE O., MANGIN A., ALEXANDRA N., COLLOMP R. The Aggregate Risk Index: An intuitive tool providing the health risks of air pollution to health care community and public. Atmospheric Environment, 46, 11, 2012.

18. ZHENG S., CAO C.X., SINGH R.P. Comparison of ground based indices (API and AQI) with satellite based aerosol products. Science of the Total Environment, 488-489, 398, 2014.

19. SHE Q., PENG X., XU Q., LONG L., WEI N., LIU M., JIA W., ZHOU T., HAN J., XIANG W. Air quality and its response to satellite-derived urban form in the Yangtze River Delta, China. Ecological Indicators, 75, 297, 2017.

20. CHEN R., WANG X., MENG X., HUA J., ZHOU Z., CHEN B., KAN H. Communicating air pollution-related health risks to the public: an application of the Air Quality Health Index in Shanghai, China. Environment International, 51, 168, 2013.

21. STIEB D.M., BURNETT R.T., SMITH-DOIRON M., BRION O., SHIN H.H., ECONOMOU V. A new multipollutant, no-threshold air quality health index based on short-term associations observed in daily timeseries analyses. Journal of the Air \& Waste Management Association, 58 (3), 435, 2008.

22. QIAO M., GU T., WANG Y., ZHAO Y., TAO Y., ZHAO $\mathrm{X}$. Construction of respiratory disease-related air quality health index in Lanzhou. Journal Environment Health, 35 (2), 99, 2018.

23. LI X., XIAO J., LIN H., LIU T., QIAN Z., ZENG W., GUO L., MA W. The construction and validity analysis of AQHI based on mortality risk: A case study in Guangzhou, China. Environmental Pollution, 220, 487, 2017.

24. WONG T.W., TARN W.W.S., YU I.T.S., LAU A.K.H., PANG S.W., WONG A.H.S. Developing a risk-based air quality health index. Atmospheric Environment, 76, 52, 2013.

25. YU H.L., LIN Y.C., KUO Y.M. A time series analysis of multiple ambient pollutants to investigate the underlying air pollution dynamics and interactions. Chemosphere, 134, 571, 2015. 
26. YANG P., ZHANG Y., WANG K., DORAISWAMY P., CHO S.H. Health impacts and cost-benefit analyses of surface $\mathrm{O}_{3}$ and $\mathrm{PM}_{2.5}$ over the U.S. under future climate and emission scenarios. Environmental Research, 178, 108687, 2019.

27. LIANG D., WANG Y., WANG Y., MA C. National air pollution distribution in China and related geographic, gaseous pollutant, and socio-economic factors. Environmental Pollution, 250, 998, 2019.

28. LELIEVELD J., BOURTSOUKIDIS E., BRUHL C., FISCHER H., FUCHS H., HARDER H., HOFZUMAHAUS A., HOLLAND F., MARNO D., NEUMAIER M., POZZER A., SCHLAGER H., WILLIAMS J., ZAHN A., ZIEREIS H. The South Asian monsoon-pollution pump and purifier. Science, 361 (6399), 270, 2018.

29. LI X., ZHANG Q., ZHANG Y., ZHENG B., WANG K., CHEN Y., WALLINGTON T.J., HAN W., SHEN W., ZHANG X. Source contributions of urban $\mathrm{PM}_{2.5}$ in the Beijing-Tianjin-Hebei region: Changes between 2006 and 2013 and relative impacts of emissions and meteorology. Atmospheric Environment, 123, 229, 2015.

30. ZHANG Z., GONG D., MAO R., KIM S.J., XU J., ZHAO $X$., MA Z. Cause and predictability for the severe haze pollution in downtown Beijing in November-December 2015. Science of the Total Environment, 592, 627, 2017.

31. LIU H., TIAN H., ZHANG K., LIU S., CHENG K., YIN S., LIU Y., LIU X., WU Y., LIU W. Seasonal variation, formation mechanisms and potential sources of $\mathrm{PM}_{2.5}$ in two typical cities in the Central Plains Urban Agglomeration, China. Science of the Total Environment, 657, 657, 2019.

32. QIU P., TIAN H., ZHU C., LIU K., GAO J., ZHOU J. An elaborate high resolution emission inventory of primary air pollutants for the Central Plain Urban Agglomeration of China. Atmospheric Environment, 86, 93, 2014.

33. GABARRON M., FAZ A., ACOSTA J.A. Use of multivariable and redundancy analysis to assess the behavior of metals and arsenic in urban soil and road dust affected by metallic mining as a base for risk assessment. Journal of Environmental Management, 206, 192, 2018.

34. BAO H., NIGGEMANN J., LUO L., DITTMAR T., KAO S.J. Aerosols as a source of dissolved black carbon to the ocean. Nature Communications, 8 (1), 510, 2017.

35. FENG W., WU Z., HUANG L., DING Y., SHI R. Larval and Juvenile Fish Assemblage Structure of Inshore Habitats in the Middle Reaches of Li River, China: Spatial and Temporal Patterns in Relation to Abiotic Factors. Russian Journal of Ecology, 49 (3), 260, 2018.

36. JIANG N., GUO Y., WANG Q., KANG P., TANG X. Chemical composition characteristics of $\mathrm{PM}_{2.5}$ in three cities in Henan, central China. Aerosol and Air Quality Research, 17 (10), 2367, 2017.

37. YIN X. Spatial and temporal statistics of atmospheric pollution in central plains economic zone, North China University of Water Resources and Electric Power, Zhengzhou: 2018 [In Chinese].

38. YANG J., JI Z., KANG S., ZHANG Q., LEE S.Y. Spatiotemporal variations of air pollutants in western China and their relationship to meteorological factors and emission sources. Environmental Pollution, 254, 112952, 2019.

39. LUVSAN M.E., SHIE R.H., PUREVDORJ T., BADARCH L., BALDORJ B., CHAN C.C. The influence of emission sources and meteorological conditions on $\mathrm{SO}_{2}$ pollution in Mongolia. Atmospheric Environment, 61, 542, 2013.

40. LIU S., HUA S., WANG K., QIU P., LIU H., WU B., SHAO P., LIU X., WU Y., XUE Y., HAO Y., TIAN H. Spatial-temporal variation characteristics of air pollution in Henan of China: Localized emission inventory, WRF/ Chem simulations and potential source contribution analysis. Science of the Total Environment, 624, 396, 2018.

41. CHEN R., CHEN B., KAN H. Air quality health index in China:a pilot study. China Environment Science, 33(11), 2081, 2013 [In Chinese]. 